\title{
The Relative Age Effect in Czech U14 Male and Female Tennis Players in 2007-2016
}

\author{
Roman Koloničný', Adrián Agricola², Michal Bozděch', Jiři Zháněl
}

${ }^{1}$ Faculty of Sports Studies, Masaryk University, Brno, Czech Republic

2University of Hradec Králové, Faculty of Education, Hradec Králové, Czech Republic

\begin{abstract}
The issue of the Relative Age Effect (RAE) has been long researched, discussed and published both in the academic and coaching community and the number of studies on it in various sports has significantly grown in recent years. The aim of this study was to verify the existence of RAE among Czech male $(n=6552)$ and female $(n=4131)$ junior tennis players and to identify possible differences in birthdate effect between male and female players. The research was carried out in players registered in the years 2007-2016 in the U14 age category in Czech Tennis Association (CTA) database; the athletes were divided into three subgroups ('Ranked,' 'Top 100', 'Top 10'). Research data were analysed by the methods of descriptive and inferential statistics: relative and absolute frequency, chi-square goodness of fit test $\left(X_{G}^{2}\right)$ and chi-square test of independence $\left(X_{1}^{2}\right)$ with the use of effect size (ES index $W$ ). A declining tendency of frequencies from Q1 to Q4 between male and female junior players was proven in all three subgroups. In the whole period of 2007-2016, a significant and strong RAE was demonstrated only in the 'Top 10' male subgroup (RAE was significant and ES was small or trivial in the other two subgroups). Among the female players, RAE was significant in all three subgroups (ES was small or trivial). Gender differences in RAE in favour of male players were significant in 'Top 100' and 'Ranked' (ES was small or trivial in all three subgroups). In the short and long term, RAE can have significant implications for the sport development of athletes; both coaches and the professional public can therefore be recommended to pay attention to this issue. The impact of RAE in sport, i.e. the uneven distribution of athletes' birthdates, is more pronounced especially among junior athletes and often significantly affects their sports development and career.
\end{abstract}

Keywords: birthdate, chronological age, racquet sports, talent identification, youth sport

\section{INTRODUCTION}

As early as at the beginning of the last century, the first researches focused on the relationship between success in education and dates of birth started to appear indicating that children born earlier in the year have better learning results (Pintner \& Forlano, 1934). The term Relative Age Effect (RAE), first used by Barnsley, Thompson and Barnsley (1985), has been mostly used for this phenomenon in recent years. Ontogenetic development occurs frequently at different speed in junior age, which may bring a temporary advantage to earlier in the year born athletes; however, this does not mean that these athletes will be successful in adulthood (Malina, 1994). Especially during the last decade, the RAE has received a great deal of attention in sports sciences as athletes born at the beginning of the year often achieve, because of this temporal biological advantage linked with a higher level of anthropometric and fitness characteristics, better athletic performances. These individuals are often referred to as athletically talented, they are more often chosen for elite junior selections, resp. training programmes, which allows them to gain better conditions for personal development, experience, contacts, motivation and better 
training facilities. A number of authors (e.g. Andronikos, Elumaro, Westbury, \& Martindale, 2016; Cobley, Baker, Wattie, \& McKenna, 2009; Fumarco, Gibbs, Jarvis, \& Rossi, 2017; GómezLópez, Granero-Gallegos, Molina, \& Ríos, 2017) state that athletes born at the beginning of a calendar year are more often selected for training programmes for talented individuals. Thus, truly talented athletes can be left out, which can have a discriminatory effect on later born players. In sports, the effect of birthdate was first researched in ice hockey (Barnsley et al., 1985), subsequently also in other sports, for instance in soccer (Barnsley, Thompson, \& Legault, 1992), baseball (Thompson, Barnsley, \& Stebelsky, 1991), gymnastics, soccer, swimming and tennis (Baxter-Jones, 1995). During the last decade, there has been a large increase in studies dealing with the RAE effect in basketball (Ibáñez, Mazo, Nascimento, \& García-Rubio, 2018), in soccer (Gil, Bidaurrazaga-Letona, Martin-Garetxana, Lekue, \& Larruskain, 2019), in handball (Rubia et al., 2020), in ice hockey (Nykodým, Bozděch, Agricola, \& Zháněl, 2020), in volleyball (Parma \& Penna, 2018), judo (Albuquerque, Franchini, Lage, Da Costa, Costa, \& Malloy-Diniz, 2015) and other sports. Most of the above-mentioned authors found a significantly higher number of athletes born in the first (Q1) and second (Q2) quartiles, i.e. in the first (S1) semester. The effect of RAE was recorded to a larger extent namely in junior categories, while, with the increasing level of competitions, the RAE influence grows stronger, while in senior categories it rather weakens. A larger RAE influence manifests itself in males; Cobley et al. (2009) in their extensive Meta-Analytical Review already registered this phenomenon in the whole spectrum of sports across all the age groups at various levels of competitions (from recreational to elite athletes). Only in a few sports, the RAE influence has not been proven, which for instance Hammer (2020) explains - in elite ski jumpers - by high technical demand on skills and the advantage of jumpers with lower weight. In most sports, athletes are classified into age categories according to their chronological age, specifically to eliminate uneven conditions between the individuals at various levels of ontogenetic development. However, even in these age-homogenous groups, there are significant differences in the mental and physical maturity of individuals, especially with regard to the RAE, as the differences between individuals can be as much as 12 months (Baker, Schorer, \& Cobley, 2010).

From the point of view of the interpretation of results of some older studies, it is rather problematic that the agreement between expected and observed data frequencies was assessed in them only with the help of null hypothesis significance testing $(\mathrm{p} \leq 0.05)$ using Pearson's chi-squared test (goodness of fit test), without using effect size (Cumming, 2013). This causes, especially in case of large files, that even small differences are statistically significant, even if effect size is only trivial or small. Therefore, we present the results of the studies in the original version in this part; for the sake of discussion, the effect size was calculated from the published data (if possible).

Many studies are devoted to the issue of RAE in tennis; both Cobley et al. (2009) and Bozděch, Nykodým, Agricola, and Zháněl (2017) state that in terms of frequency of publications, tennis takes third place after soccer and ice hockey.

It was already Baxter-Jones (1995), resp. Dudink (1994), who showed that up to 85 percent of elite British junior players were born in the first half of the year (S1); respectively almost half of 60 elite Dutch junior tennis players aged 12-16 were born in Q1. Studies by other authors also confirmed significant differences between the first and second 6 months of the calendar year, resp. between individual quartiles Q1-Q4. Filipčič (2001) observed no RAE among Slovenian male and female junior tennis players (12-18 let), while a significantly higher representation in Q1 was found in male players in U12-U16 categories, while in female players only in U12-U14 categories. The author explains the stronger influence of RAE in categories of boys by the earlier completion of biological development in girls and the consequent faster maturation. Edgar and O'Donoghue (2005) demonstrated significant RAE both among elite senior female and male 
players and among elite female and male junior players. In a follow-up study, O’Donoghue (2009) also found significant RAE both in female and in male elite junior players. In an interesting study related to our research, Loffing, Schorer, and Cobley, 2010 dealt with the issue of RAE in relation to handedness in a large group of senior professional tennis players $(n=1027$; Top 500 of the ATP). The authors showed a significant influence in right-handers (RH), but no influence in left-handers $(\mathrm{LH})$ which they explain by a smaller number of left-handers.

The results of recent studies have also shown a RAE influence especially in junior categories, both in boys and girls. Ribeiro Júnior, et al. (2013) demonstrated more than a half of athletes born in S1 among Brazil female and male junior tennis players (U14 and U18) - also among professional players - while in the U16 category, their number reached about 50 percent. Pacharoni, Aoki, Costa, Moreira, and Massa (2014) found that, in all age categories (U12-U18), more than a half of male junior tennis players (65.2\%) were born in S1. Ulbricht, Fernandez-Fernandez, Mendez-Villanueva, and Ferrauti, (2015) found in German male junior tennis players that, with increasing level of performance, also the number of players born in the first semester (S1) had grown. Agricola, Zháněl, and Bozděch (2017) observed significant RAE both in male and female junior players (U14, World Junior Tennis Finals 2007-2011), similarly to Moreira, Lopes, Faria, \& Albuquerque (2017) in junior male tennis players (U14). Romann, Rössler, Javet, and Faude (2018) also found in Swiss talent development programme participants (U14, STDP, 25 largest sports) that more of them - both among female and among male junior tennis players - were born in S1. The authors also proved that the highest representation in S1 in 25 largest sports had been found among junior female athletes in badminton and among junior male athletes in soccer/ football. Sögüt et al. (2019) dealt with the effects of age and maturity on various anthropometric and fitness characteristics in young female tennis players (U12-U14) and demonstrated a significant difference in test results in favour of players born in S1 compared to those born in S2.

Some authors point out the fact that RAE may lead - in later born, i.e. relatively younger players - to a loss of motivation, lack of interest in tennis as well as to a premature termination of sports career (so called dropout). Potential benefits of earlier born players must be perceived in the context of the necessity and importance of providing equal conditions and opportunities for each athlete regardless the date of birth (Edgar \& O’Donoghue, 2005; Myburgh, Cumming, Coelho e Silva, Cooke, \& Malina, 2016; O’Donoghue, 2014; Romann et al., 2018). It is clear from the above given synthesis of the findings that the influence of RAE is demonstrable and indispensable especially in junior tennis.

The aim of the study was to verify RAE existence among Czech male and female junior tennis players in 2007-2016 and identify possible sex differences in three subgroups ('Ranked', 'Top 100', 'Top 10').

\section{MATERIAL AND METHOD}

\section{Participants}

The research sample consisted of Czech male and female junior tennis players, who were - during 2007-2016 - registered in the U14 age category in the official rankings (ttp://www.cztenis. $\mathrm{cz} / \mathrm{mladsi}$-zactvo/zebricky) of the Czech Tennis Association (CTA), with full respect to the legal requirements for the protection of personal data (data were anonymized). Three subgroups were subsequently formed from the sample: the first subgroup, defined as 'Ranked' players (male: $n_{M}$ =6552; female: $\left.n_{F}=4131\right)$; the two other subgroups were defined as 'Top 100' $\left(n_{M}=933\right.$; $n_{F}=$ 837 ) and 'Top 10' ( $\left.n_{M}=100 ; n_{F}=99\right)$; the existence of RAE is generally determined by testing the statistical significance of the difference between the observed distribution of birth dates (sample) 
and the expected theoretical distribution (population), (Delorme, \& Champely, 2015). Players' birthdates were distributed to four quartiles according to the month of birth as follows: Q1 (January to March), Q2 (April to June), Q3 (July to September) and Q4 (October to December). The expected frequency of the birthdate of Czech same age population was obtained from the publicly available sources (https://www.czso.cz); theoretical (expected) frequency distribution was: $\mathrm{Q}_{1}=25 \%, \mathrm{Q}_{2}=27 \%, \mathrm{Q}_{3}=25 \%, \mathrm{Q}_{4}=23 \%$.

\section{Data analysis}

The chi-square goodness of fit test $\left(\chi_{G}^{2} ; \mathrm{df}=3\right)$ was used to test the significance of differences between the observed and expected frequencies of birthdate; to determine the association between the samples of male and female players (in groups 'Ranked', 'Top 100', 'Top 10'), we used the chisquare test of independence $\left(\chi_{I}^{2}\right)$. Cumming (2013), Hopkins (2016), Sullivan, and Feinn, (2012) and other authors consider estimation based on the effect size (ES) to be a much better method than mere testing significance of null hypothesis. In case of a conflict between the conclusions gained by both methods, we therefore lean towards the results of ES, also due to the deliberate selection of research sample. The evaluation of ES index $w$ was interpreted as small $(w=0.10)$, medium $(\mathrm{w}=0.30)$ or large $(\mathrm{w}=0.50)$ based on Cohen $(1988)$ with the use of later Hopkins' (2016) more detailed division: trivial $(w=.0)$, small $(w=.10)$, moderate $(\mathrm{w}=.30)$, large $(\mathrm{w}=.50)$, very large $(\mathrm{w}=.70)$, nearly perfect $(\mathrm{w}=.90)$, perfect $(\mathrm{w}=1.0)$. Calculations were performed with the IBM SPSS Statistics software (version 25.0, SPSS INC., Chicago, IL USA) and Microsoft Excel (the level of significance was set at $\mathrm{p} \leq 0.05$ ).

\section{RESULTS}

Figure 1 presents the distribution of relative frequencies of male junior players' birthdates (U14) in individual groups ('Ranked', 'Top 100', 'Top 10') in 2007-2016. In all three groups of male players, there is an obvious markedly declining tendency of frequency distribution from Q1 to Q4, but only in Q1, with a decreasing level of performance (from 'Top 10' to 'Ranked'), the influence of RAE also decreases.

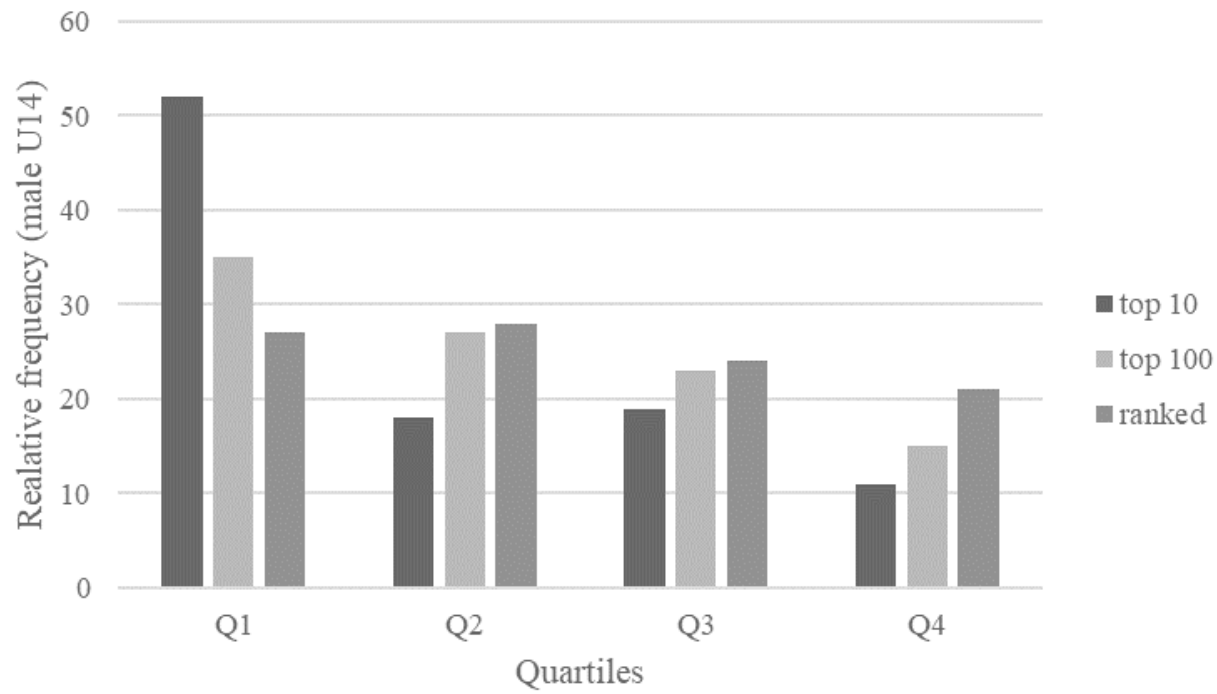


Figure 1. Distribution of relative frequencies (\%) male junior players (U14) in 2007-2016

Table 1 summarizes the results of the statistical assessment of RAE in male junior players (U14) in individual years as well as during the whole period of 2007-2016. Among the 'Ranked' male players, mostly no significant RAE was observed (ES was small, resp. trivial each year); among 'Top 100', there exists a significant and medium RAE in 50\% of years, in the other half of the years, no RAE was observed. No significant RAE was observed in 'Top 10'; ES was large or medium, in six cases it was impossible to perform a statistical evaluation because of zero frequency in some quartiles. In the whole monitored period of 2007-2016, a significant and strong RAE was observed in 'Top 10'; in the other two subgroups ('Ranked', 'Top 100'), a significant RAE was observed; ES was small, resp. trivial. During the observed period in the individual subgroups, 55\% athletes born in the 1st semester (S1) were among the 'Ranked', $62 \%$ among the 'Top 100' and 70\% among 'Top 10' male players, which indicates increasing impact of RAE with growing athletic performance.

Table 1. Birth distribution of Czech male junior tennis players

\begin{tabular}{|c|c|c|c|c|c|c|c|c|c|c|c|c|c|c|}
\hline Years & Status & Q1 & $\%$ & Q2 & $\%$ & Q3 & $\%$ & Q4 & $\%$ & $\mathrm{n}$ & $\chi_{G}^{2}$ & $\mathrm{p}$ & wG & ES \\
\hline \multirow[t]{3}{*}{2007} & top 10 & 4 & 40 & 1 & 10 & 5 & 50 & 0 & 0 & 10 & $-^{*}$ & $-^{*}$ & $-^{*}$ & $-^{\star}$ \\
\hline & top 100 & 33 & 36 & 24 & 26 & 24 & 26 & 11 & 12 & 92 & 9.30 & 0.03 & 0.32 & medium \\
\hline & ranked & 196 & 29 & 174 & 26 & 172 & 26 & 125 & 19 & 667 & 10.76 & 0.01 & 0.13 & small \\
\hline \multirow[t]{3}{*}{2008} & top 10 & 5 & 50 & 1 & 10 & 2 & 20 & 2 & 20 & 10 & 3.71 & 0.30 & 0.61 & large \\
\hline & top 100 & 37 & 40 & 23 & 25 & 15 & 16 & 18 & 19 & 93 & 11.77 & 0.01 & 0.36 & medium \\
\hline & ranked & 191 & 28 & 203 & 29 & 164 & 24 & 135 & 19 & 693 & 7.39 & 0.06 & 0.10 & small \\
\hline \multirow[t]{3}{*}{2009} & top 10 & 6 & 60 & 3 & 30 & 0 & 0 & 1 & 10 & 10 & $-^{*}$ & $-^{\star}$ & $-^{*}$ & $-^{\star}$ \\
\hline & top 100 & 36 & 38 & 28 & 30 & 14 & 15 & 16 & 17 & 94 & 12.22 & 0.01 & 0.36 & medium \\
\hline & ranked & 182 & 28 & 184 & 28 & 155 & 24 & 132 & 20 & 653 & 5.11 & 0.16 & 0.09 & trivial \\
\hline \multirow[t]{3}{*}{2010} & top 10 & 8 & 80 & 0 & 0 & 2 & 20 & 0 & 0 & 10 & $-^{*}$ & $-^{*}$ & $-^{*}$ & $-^{\star}$ \\
\hline & top 100 & 33 & 35 & 23 & 24 & 22 & 23 & 16 & 17 & 94 & 5.62 & 0.13 & 0.25 & small \\
\hline & ranked & 173 & 28 & 175 & 29 & 140 & 23 & 120 & 20 & 608 & 7.38 & 0.06 & 0.11 & small \\
\hline \multirow[t]{3}{*}{2011} & top 10 & 6 & 60 & 2 & 20 & 1 & 10 & 1 & 10 & 10 & 6.72 & 0.08 & 0.82 & very large \\
\hline & top 100 & 33 & 35 & 31 & 33 & 19 & 20 & 12 & 13 & 95 & 10.11 & 0.02 & 0.33 & medium \\
\hline & ranked & 159 & 27 & 179 & 30 & 130 & 22 & 119 & 20 & 587 & 7.49 & 0.06 & 0.11 & small \\
\hline \multirow[t]{3}{*}{2012} & top 10 & 5 & 50 & 3 & 30 & 2 & 20 & 0 & 0 & 10 & $-^{*}$ & $-^{\star}$ & $-^{*}$ & $-^{\star}$ \\
\hline & top 100 & 35 & 37 & 27 & 29 & 23 & 24 & 9 & 10 & 94 & 13.11 & 0.00 & 0.37 & medium \\
\hline & ranked & 176 & 28 & 175 & 27 & 153 & 24 & 135 & 21 & 639 & 2.95 & 0.40 & 0.07 & trivial \\
\hline \multirow[t]{3}{*}{2013} & top 10 & 5 & 50 & 2 & 20 & 3 & 30 & 0 & 0 & 10 & - & $-^{*}$ & $-^{*}$ & $-^{*}$ \\
\hline & top 100 & 27 & 29 & 23 & 24 & 24 & 26 & 20 & 21 & 94 & 0.88 & 0.83 & 0.10 & small \\
\hline & ranked & 174 & 25 & 184 & 27 & 192 & 28 & 144 & 21 & 694 & 3.56 & 0.31 & 0.07 & trivial \\
\hline \multirow[t]{3}{*}{2014} & top 10 & 5 & 50 & 2 & 20 & 1 & 10 & 2 & 20 & 10 & 3.62 & 0.31 & 0.60 & large \\
\hline & top 100 & 29 & 32 & 27 & 29 & 22 & 24 & 14 & 15 & 92 & 4.22 & 0.24 & 0.21 & small \\
\hline & ranked & 178 & 26 & 194 & 29 & 155 & 23 & 145 & 22 & 672 & 3.06 & 0.38 & 0.07 & trivial \\
\hline \multirow[t]{3}{*}{2015} & top 10 & 5 & 50 & 3 & 30 & 0 & 0 & 2 & 20 & 10 & $-^{*}$ & $-^{\star}$ & $-^{*}$ & $-^{*}$ \\
\hline & top 100 & 32 & 35 & 29 & 32 & 19 & 21 & 12 & 13 & 92 & 8.88 & 0.03 & 0.31 & medium \\
\hline & ranked & 172 & 26 & 208 & 31 & 149 & 22 & 139 & 21 & 668 & 7.72 & 0.05 & 0.11 & small \\
\hline \multirow[t]{3}{*}{2016} & top 10 & 3 & 30 & 1 & 10 & 3 & 30 & 3 & 30 & 10 & 1.48 & 0.69 & 0.39 & medium \\
\hline & top 100 & 29 & 31 & 21 & 23 & 28 & 30 & 15 & 16 & 93 & 4.97 & 0.17 & 0.23 & small \\
\hline & ranked & 167 & 25 & 187 & 28 & 171 & 25 & 146 & 22 & 671 & 0.70 & 0.87 & 0.03 & trivial \\
\hline \multirow{3}{*}{$\begin{array}{l}2007- \\
2016\end{array}$} & top 10 & 52 & 52 & 18 & 18 & 19 & 19 & 11 & 11 & 100 & 39.86 & 0.00 & 0.63 & large \\
\hline & top 100 & 324 & 35 & 256 & 27 & 210 & 23 & 143 & 15 & 933 & 61.58 & 0.00 & 0.26 & small \\
\hline & ranked & 1768 & 27 & 1863 & 28 & 1581 & 24 & 1340 & 21 & 6552 & 35.79 & 0.00 & 0.07 & trivial \\
\hline
\end{tabular}

Note: ${ }^{\star}=$ insufficient group size, $\mathrm{Q}_{\mathrm{i}}=$ quartile, $\chi_{G}^{2}=$ chi-square test (goodness of fit), $p=$ level of significance, $w_{G}=$ effect size index, ES = effect size, $n=$ number of players in Top 100 (The number is lower in some cases due to the fact that also the players from the category of U12 took place in rankings and were not therefore included in 
the analysis.)

Figure 2 shows the distribution of the relative frequencies of female junior players' birthdates (U14) in individual subgroups during 2007-2016, giving a significant downward trend of distribution of frequencies from Q1 to Q4; however, only in Q1 also the impact of RAE decreases together with a dropping level of performance (from 'Top 10' to 'Ranked').

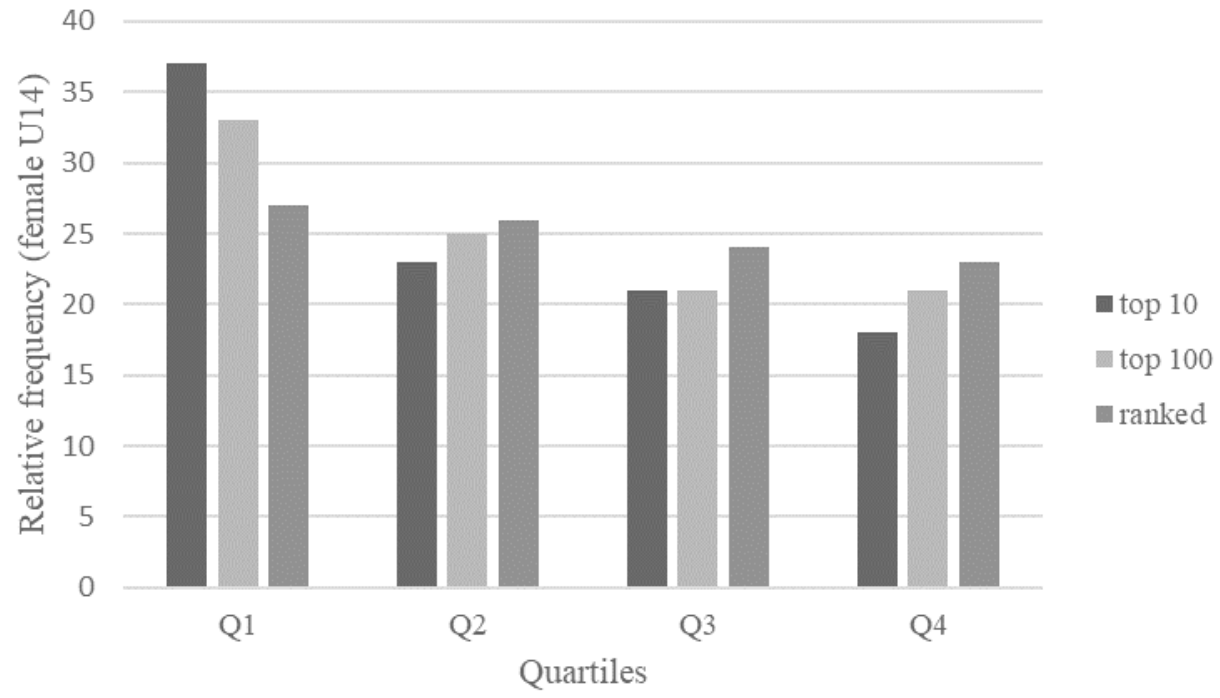

Figure 2. Distribution of relative frequencies (\%) female junior players (U14) in 2007-2016

Table 2 presents the result of statistical assessment of RAE in a sample of female junior players (U14) in the individual years as well as in the whole period of 2007-2016. Among the 'Ranked' players, a significant RAE was observed only in 2011 (ES was medium) and 2013 (ES was small). Among the 'Top 100' players, a significant RAE was observed only in 2008 and 2011 (ES was medium). In the 'Top 10' subgroups, no significant RAE was observed all years, but ES was very large (2 players), large (4 players) or medium (3 players). In the whole period of 2007-2016, a significant RAE was found in all subgroups (which is, however, rather the consequence of a large size of files), but ES was small, resp. trivial. During the observed period in the individual subgroups, 53\% athletes were born among 'Ranked', 58\% among 'Top 100' and 60\% among 'Top 10 ' female players in the first semester (S1), which indicates an increasing impact of RAE with growing sports performance (however, percentage values are lower than among the male players). 
STUDIA SPORTIVA 2021/2

Table 2. Birth distribution of Czech female junior tennis players

\begin{tabular}{|c|c|c|c|c|c|c|c|c|c|c|c|c|c|c|}
\hline Years & Status & $\mathrm{Q}_{1}$ & $\%$ & $\mathrm{Q}_{2}$ & $\%$ & $\mathrm{Q}_{3}$ & $\%$ & $\mathrm{Q}_{4}$ & $\%$ & $n$ & $\chi_{G}^{2}$ & $p$ & $w_{G}$ & ES \\
\hline \multirow[t]{3}{*}{2007} & top 10 & 6 & 60 & 1 & 10 & 2 & 20 & 1 & 10 & 10 & 6.81 & 0.08 & 0.83 & very large \\
\hline & top 100 & 32 & 37 & 20 & 23 & 18 & 25 & 16 & 19 & 86 & 6.87 & 0.08 & 0.28 & small \\
\hline & ranked & 123 & 29 & 99 & 23 & 108 & 25 & 96 & 23 & 426 & 4.85 & 0.18 & 0.11 & small \\
\hline \multirow[t]{3}{*}{2008} & top 10 & 3 & 30 & 1 & 10 & 2 & 20 & 4 & 40 & 10 & 2.53 & 0.47 & 0.50 & large \\
\hline & top 100 & 29 & 37 & 14 & 18 & 14 & 18 & 22 & 28 & 79 & 9.33 & 0.03 & 0.34 & medium \\
\hline & ranked & 117 & 28 & 97 & 23 & 96 & 23 & 104 & 25 & 414 & 5.07 & 0.17 & 0.11 & small \\
\hline \multirow[t]{3}{*}{2009} & top 10 & 3 & 30 & 1 & 10 & 2 & 20 & 4 & 40 & 10 & 2.53 & 0.47 & 0.50 & large \\
\hline & top 100 & 24 & 29 & 16 & 20 & 20 & 24 & 22 & 27 & 82 & 2.84 & 0.42 & 0.19 & small \\
\hline & ranked & 97 & 25 & 117 & 30 & 100 & 26 & 77 & 20 & 391 & 3.15 & 0.37 & 0.09 & trivial \\
\hline \multirow[t]{3}{*}{2010} & & 4 & 40 & 3 & 30 & 2 & 20 & 1 & 10 & 10 & 1.77 & 0.62 & 0.42 & medium \\
\hline & top 100 & 29 & 36 & 21 & 25 & 18 & 22 & 15 & 18 & 83 & 4.61 & 0.20 & 0.24 & small \\
\hline & ranked & 110 & 27 & 101 & 25 & 115 & 28 & 86 & 10 & 412 & 3.63 & 0.31 & 0.09 & trivial \\
\hline \multirow[t]{3}{*}{2011} & top 10 & 3 & 30 & 4 & 40 & 2 & 20 & 1 & 10 & 10 & 1.56 & 0.67 & 0.40 & medium \\
\hline & top 100 & 34 & 40 & 25 & 29 & 14 & 16 & 13 & 15 & 86 & 12.34 & 0.01 & 0.38 & medium \\
\hline & ranked & 110 & 30 & 70 & 19 & 104 & 29 & 78 & 22 & 362 & 37.39 & 0.00 & 0.32 & medium \\
\hline \multirow[t]{3}{*}{2012} & top 10 & 2 & 22 & 4 & 44 & 2 & 22 & 1 & 11 & 9 & 1.62 & 0.65 & 0.43 & medium \\
\hline & top 100 & 26 & 33 & 22 & 28 & 11 & 14 & 20 & 25 & 79 & 6.06 & 0.11 & 0.28 & small \\
\hline & ranked & 105 & 28 & 102 & 27 & 73 & 20 & 91 & 25 & 371 & 6.23 & 0.10 & 0.13 & small \\
\hline \multirow[t]{3}{*}{2013} & top 10 & 4 & 40 & 5 & 50 & 0 & 0 & 1 & 10 & 10 & $-^{*}$ & $-^{*}$ & $-^{*}$ & $-^{*}$ \\
\hline & top 100 & 28 & 35 & 20 & 25 & 14 & 17 & 19 & 23 & 81 & 5.06 & 0.17 & 0.25 & small \\
\hline & & 102 & 26 & 122 & 31 & 66 & 17 & 100 & 26 & 390 & 14.22 & 0.00 & 0.19 & small \\
\hline \multirow[t]{3}{*}{2014} & top 10 & 5 & 50 & 2 & 20 & 1 & 10 & 2 & 20 & 10 & 3.62 & 0.31 & 0.60 & large \\
\hline & top 100 & 27 & 32 & 24 & 28 & 18 & 21 & 16 & 19 & 85 & 2.75 & 0.43 & 0.18 & small \\
\hline & ranked & 114 & 26 & 125 & 29 & 104 & 24 & 94 & 22 & 437 & 1.30 & 0.73 & 0.05 & trivial \\
\hline \multirow[t]{3}{*}{2015} & top 10 & 5 & 50 & 1 & 10 & 2 & 20 & 2 & 20 & 10 & 3.71 & 0.30 & 0.61 & large \\
\hline & top 100 & 18 & 22 & 28 & 34 & 25 & 30 & 11 & 13 & 82 & 6.12 & 0.11 & 0.27 & small \\
\hline & ranked & 111 & 23 & 134 & 28 & 126 & 27 & 103 & 22 & 474 & 1.57 & 0.67 & 0.06 & trivial \\
\hline \multirow[t]{3}{*}{2016} & top 10 & 2 & 20 & 1 & 10 & 6 & 60 & 1 & 10 & 10 & 6.81 & 0.08 & 0.83 & very large \\
\hline & top 100 & 29 & 31 & 18 & 19 & 27 & 29 & 20 & 21 & 94 & 4.08 & 0.25 & 0.21 & small \\
\hline & ranked & 122 & 27 & 111 & 24 & 111 & 24 & 110 & 24 & 454 & 2.08 & 0.56 & 0.07 & trivial \\
\hline \multirow[t]{3}{*}{$2007-2016$} & top 10 & 37 & 37 & 23 & 23 & 21 & 21 & 18 & 18 & 99 & 8.15 & 0.04 & 0.29 & small \\
\hline & top 100 & 276 & 33 & 208 & 25 & 179 & 21 & 174 & 21 & 837 & 28.88 & 0.00 & 0.19 & small \\
\hline & ranked & 1111 & 27 & 1078 & 26 & 1003 & 24 & 939 & 23 & 4131 & 8.17 & 0.04 & 0.04 & trivial \\
\hline
\end{tabular}

Note: $-^{*}=$ insufficient group size, $\mathrm{Qi}=$ quartile, $\chi_{G}^{2}=$ chi-square test (goodness of fit), $\mathrm{p}=$ level of significance, $\mathrm{w}_{\mathrm{G}}=$ effect size index, $\mathrm{ES}=$ effect size, $\mathrm{n}=$ number of players in Top 100 (The number is lower in some cases due to the fact that also the players from the category of U12 took place in rankings and were not therefore included in the analysis.)

Table 3 shows the results of the assessment of sex-differences of RAE between the male and female samples ('Ranked', 'Top 100', 'Top 10'). Although in case of 'Top 100' and 'Ranked' subgroups, the sex-differences in favour of male players are significant (again, rather due to the large size of the files); they are trivial in terms of ES. 
Table 3. Comparison of RAE in male and female tennis players in 2007-2016

\begin{tabular}{|c|c|c|c|c|c|c|c|c|c|c|c|c|c|c|c|c|c|}
\hline Gender & Status & $\mathrm{Q}_{1}$ & $\%$ & $\mathrm{Q}_{2}$ & $\%$ & $\mathrm{Q}_{3}$ & $\%$ & $\mathrm{Q}_{4}$ & $\%$ & $n$ & $\chi_{G}^{2}$ & $p$ & $w_{G}$ & $\chi_{I}^{2}$ & $p$ & $w_{I}$ & ES \\
\hline male & top 10 & 52 & 52 & 18 & 18 & 19 & 19 & 11 & 11 & 100 & 39.86 & 0.00 & 0.63 & \multirow{2}{*}{4.92} & \multirow{2}{*}{0.18} & \multirow{2}{*}{0.16} & \multirow{2}{*}{ small } \\
\hline female & top 10 & 37 & 37 & 23 & 23 & 21 & 21 & 18 & 18 & 99 & 8.15 & 0.04 & 0.29 & & & & \\
\hline male & top 100 & 324 & 35 & 256 & 27 & 210 & 23 & 143 & 15 & 933 & 61.58 & 0.00 & 0.26 & \multirow{2}{*}{9.13} & \multirow{2}{*}{0.03} & \multirow{2}{*}{0.07} & \\
\hline female & top 100 & 276 & 33 & 208 & 25 & 179 & 21 & 174 & 21 & 837 & 28.88 & 0.00 & 0.19 & & & & \\
\hline male & ranked & 1768 & 27 & 1863 & 28 & 1581 & 24 & 1340 & 21 & 6552 & 35.79 & 0.00 & 0.07 & \multirow{2}{*}{11.23} & \multirow{2}{*}{0.01} & \multirow{2}{*}{0.03} & \multirow{2}{*}{ trivial } \\
\hline female & ranked & 1111 & 27 & 1078 & 26 & 1003 & 24 & 939 & 23 & 4131 & 8.17 & 0.04 & 0.04 & & & & \\
\hline
\end{tabular}

Note: $\chi_{I}^{2}=$ chi-square test (independence), $w_{I} w_{I}=$ effect size index (independence)

\section{DISCUSSION}

Comparison of the results of our study with the results of other authors was possible only in a relatively small number of similar studies. The very first studies already showed in elite young British athletes (without statistical verification) that almost half of male and female tennis players was born in the first quartile (Baxter-Jones, 1995); there was also a significant birthdate influence found in U12 and U14 among Slovenian female tennis players (Filipčič, 2001).

Edgar and O'Donoghue (2005) showed a significant RAE existence among elite female and male junior tennis players; the effect size was medium. Significant, but small RAE was also found by O'Donoghue (2009a) among elite female and male junior players' world rankings (with the exception of 2005) and also in a similar study (2009b) among the ITF ranked (end 2003, resp. 2008) female and male junior players. Recent studies have proven significant and medium RAE in the World Junior Tennis Finals (WJTF, 2007-11) for all female junior players and semi-finalists (Agricola, Zháněl, \& Bozděch, 2017); similarly, Bozděch et al. (2017) have found significant and large RAE among all male tennis players and semi-finalists in the WJTF 2012-16. In the study which was the main inspiration for this research, Gerdin, Hedberg and Hageskog (2018) demonstrated a significant, but small RAE among junior tennis players in Sweden (13-16 years old, subgroups 'Ranked', 'Top 50' and 'Top 10') among 'Ranked' and 'Top 50' female players; while no significant and medium RAE was demonstrated among 'Top 10' female players. There was no significant and small RAE found among the male players in all 3 subgroups. While Gerdin et al. (2018) demonstrated no significant and medium RAE only among 'Top 10' female players, significant and strong RAE in 'Top 10' male players during the WJTF was proven in our study. The authors further noted - in correspondence with similar studies in soccer (Vincent, \& Glamser, 2006) and swimming (Costa et al., 2013) - a stronger effect of the RAE in favour of female tennis players (although ES was only small, resp. trivial); this study presented by us found a stronger effect of RAE among male players (ES also small, resp. trivial). Romann et al. (2018) observed significant RAE among junior female tennis players in the Swiss talent development programme (ES was medium).

A number of other studies have also been published aimed at RAE among juniors in various sports. Delorme, along with various co-authors, found in three studies that a significant RAE had been observed among U14 female basketball players (Delorme, \& Raspaud, 2009; Delorme, Chalabaev, \& Raspaud, 2011) and in U14 female soccer players (Delorme, Boiché, \& Raspaud (2010); ES was small or trivial. Hancock (2017) also found a significant RAE among female and male ice hockey players aged 13-14 (ES was small); similarly, as Gorski, Rosser, Hoppeler and Vogt (2016) among 13- and 14-year-old female and male Swiss Alpine skiers (significant RAE, ES small). Only Gómez-López et al. (2017) did not prove existence of any significant RAE 
(Spanish Championship: ES was medium; Spanish Cup: ES small) among 16-year-old female and male handball players. Krahenbühl and Leonardo (2020) considered the fact that relatively older female junior handball players (born in S1) had played almost twice as much time in matches than younger players (born in S2) a consequence of RAE existence as coaches had considered them better players.

The results of RAE research among senior elite athletes have often been varied; Savassifigueiredo et al. (2020) showed a significant RAE (ES was trivial) for both sexes among elite beach handball athletes, Edgar and O'Donoghue (2005) in female and male elite senior tennis players (ES was small), Nykodým et al. (2020) in elite senior ice hockey players (ES was small)), Bozděch et al. (2020) in elite tennis players - Top 100 ATP 2016-2018 (ES was small).In contrast, no significant RAE (ES was medium) was found among professional Spanish footballers/soccer players (Gil et al., 2019) and also among male and female elite ski jumpers (ES was trivial) between the first and second semester (Hammer, 2020). Parma and Penna (2018) did not prove any RAE among women's elite volleyball players in Brazil (ES trivial), but they proved it among male athletes (ES medium); thus, similarly as in our study, a stronger impact of RAE was demonstrated in men.

As a result of RAE, the earlier born athletes are often, especially in junior age, favoured over their peers due to earlier maturation of their physical, physiological and mental condition. Relatively younger players, who may have a great potential for athletic success, but they are not given enough attention, may - for this reason - prematurely terminate their athletic career (dropout). Therefore, a necessary precondition for optimal development of all athletes is the provision of equal opportunities both in training and in communication with coaches (Cobley et al., 2009; Fraser-Thomas, Coté, \& Deakin, 2008; Musch \& Grondin, 2001).

\section{CONCLUSION}

The study was focused on assessing whether there exists any RAE among Czech junior male and female tennis players in the U14 age category. The results of the study showed variety in the incidence of RAE in various performance subgroups ('Ranked,' 'Top 100', 'Top 10'). A significant RAE was detected among all the male subgroups, but only among the 'Top 10' players it was strong in terms of effect size. Among female players, RAE was significant in all three subgroups, but only weak in terms of effect size. Gender differences in RAE were significant in 'Top 100' and 'Ranked' in favour of male players, but in all three subgroups they were negligible as to effect size. The impact of RAE was therefore more pronounced in male players. Comparison of the results of this study with the conclusions of other authors suggests that RAE is more pronounced in physically demanding sports in contrast with sports where performance depends on technical and motor skills. This leads us to the consideration whether the identification of talents and the selection of junior tennis players based mainly on physical, anthropometric and performance factors is, with regard to possible RAE influence, a suitable method for predicting future development of athletes. The results of this study can help increase the awareness of tennis coaches as well as parents about the impact of RAE and thus contribute to reducing the possible occurrence of dropout in junior tennis. With regard to the fact that, during the identification of talent and implementation of training process, RAE can have - both in short and long term - a great impact on athletic development of an individual, it is really important to recommend coaches as well as the professional public to give their full attention to this issue. 


\section{REFERENCES}

Agricola A., Zháněl, J., \& Bozděch, M. (2017). The comparison of the influence of the age effect between elite junior male and female tennis players. In M. Zvonař, \& Z. Sajdlová (eds.). The 11th International Conference on Kinanthropology, "Sport and Quality of Life", 313-321. Brno: Masaryk University.

Albuquerque, M. R., Franchini, E., Lage, G. M., Da Costa, V.T., Costa, I. T., \& Malloy-Diniz, L. F. (2015). The relative age effect in combat sports: an analysis of Olympic Judo athletes, 1964-2012. Perceptual and Motor Skills, 121(1), 300-308.

Andronikos, G., Elumaro, A. I., Westbury, T., \& Martindale, R. J. J. (2016). Relative age effect: implications for effective practice. Journal of Sports Sciences, 34(12), 1124-1131. DOI: 10.1080/02640414.2015.1093647.

Baker, J., Schorer, J. \& Cobley, S. (2010). Relative Age Effects. Sportwissenschaft, 40(1), 26-30.

Barnsley, R. H., Thompson, A. H., \& Barnsley, P. E. (1985). Hockey Success and Birthdate: The Relative Age Effect. Physical Education and Recreation Journal, 51(8), 23-28.

Barnsley, R. H., Thompson, A. H., \& Legault, P. (1992). Family Planning: Football Style: The Relative Age Effect in Football. International Review of Sport Sociology, 27(1), 78-87.

Baxter-Jones, A. D. G. (1995). Growth and development of young athletes: Should competition levels be age related? Sports Medicine, 20(2), 59-64.

Bozděch, M., Nykodým, J., Agricola, A., \& Zháněl, J. (2017). The relative age effect in the world junior tennis finals 2012-2016 (male). In M. Zvonař \& Z. Sajdlová (Eds.), The 11th International Conference on Kinanthropology , „Sport and Quality of Life", 322-330. Brno: Masaryk University.

Bozděch, M., Agricola, A., Nykodým, J., Zderčík, A., \& Vodička, T. (2020). The Relative Age Effect in the Top 100 ATP Tennis Players 2016-2018. In J. Cacek, Z. Sajdlová, \& K. Šimková (Eds.). The 12th International Conference on Kinanthropology, "Sport and Quality of Life", 240-247. https://doi.org/10.5817/CZ.MUNI.P210-9631-2020-31.

Cobley, S., Baker, J., Wattie, N., \& McKenna, J. (2009). Annual Age-Grouping and Athlete Development: A Meta-Analytical Review of Relative Age Effect in Sports. Sports Medicine, 39(3), 235-256.

Cohen, J. (1988). Statistical power analysis for the behavioral sciences (2nd ed.). Hillsdale, NJ: Erlbaum.

Costa, A. M., Marques, M. C., Louro, H., Ferreira, S. S., \& Marinho, D. A. (2013). The relative age effect among elite youth competitive swimmers. European Journal of Sport Science, 13(5), 437-444.

Cumming, G. (2013). The New Statistics: A How-To Guide. Australian Psychologist, 48(3), 161-170. DOI: 10.1111/ap.12018.

Delorme, N., \& Raspaud, M. (2009). The relative age effect in young French basketball players: a study on the whole population. Scandinavian Journal of Medicine \& Science in Sports, 19(2), 235-242. https://doi.org/10.1111/j.16000838.2008.00781.x.

Delorme, N., Boiché, J., \& Raspaud, M. (2010). Relative Age Effect in Female Sport: A Diachronic Examination of Soccer Players. Scandinavian Journal of Medicine \& Science in Sports, 20(3), 509-515.

Delorme, N., \& Champely, S. (2015). Relative Age Effect and chi-squared statistics. International Review for the Sociology of Sport, 50, 740-746.

Delorme, N., Chalabaev, A., \& Raspaud M. (2011). Relative age is associated with sport dropout: evidence from youth categories of French basketball. Scandinavian Journal of Medicine and Science in Sports, 21, 120-128. doi: 10.1111/j.16000838.2009.01060.x.

Dudink, A. (1994). Birth date and sporting success. Nature, 368(6472), 592-592.

Edgar, S., \& O'Donoghue, P. (2005). Season of birth distribution of elite tennis players. Journals of Sports Sciences, 23(10), 1013-1020.

Filipčič, A. (2001). Birth date and success in tennis. Coaching \& Sport Science Review, 23, 9-11.

Fraser-Thomas, J., Coté, J., \& Deakin, J. (2008). Examining adolescent sport dropout and prolonged engagement from a developmental perspective. Journal of Sport Psychology, 20, 318-333.

Fumarco, L., Gibbs, B. G., Jarvis, J. A., \& Rossi, G. (2017). The relative age effect reversal among the National Hockey League elite. Plos One, 12(8), e0182827.

Gerdin, G., Hedberg, M., \& Hageskog, C. A. (2018). Relative age effect in Swedish male and female tennis players born in 1998-2001. Sports, 6(2), 38.

Gil, S.M., Bidaurrazaga-Letona, I., Martin-Garetxana, I., Lekue, J.A. \& Larruskain, J. (2019). Does birth date influence career attainment in professional soccer? Science and Medicine in Football, DOI: 10.1080/24733938.2019.1696471.

Gómez-López, M., Granero-Gallegos, A., Molina, S. F., \& Ríos, L. J. C. (2017). Relative age effect during the selection of young handball player. Journal of Physical Education and Sport, 17(1), 418. https://doi.org/DOI:10.7752/jpes.2017.01062.

Gorski, T., Rosser, T., Hoppeler, H., \& Vogt, M. (2016). Relative Age Effect in Young Swiss Alpine Skiers From 2004 to 2011. International Journal of Sports Physiology and Performance, 11, 455-463. http://dx.doi.org/10.1123/ijspp.2014-0418.

Hammer, T. (2020). Relative age effect in international ski jumping: analysis of FIS World Cup and FIS Junior World Ski Championships. Journal of Physical Education and Sport, 20(3), 1455-1460. https://doi.org/DOl:10.7752/jpes.2020.03200.

Hancock, D. J. (2017). Female relative age effects and the second-quartile phenomenon in young female ice hockey players. Psychology of Sport and Exercise 32, 12-16. http://dx.doi.org/10.1016/j.psychsport.2017.05.002.

Hopkins, W.G. (2016). A New View of Statistics. Retrieved from https://www.sportsci.org/resource/stats/index.html.

Ibáñez, S. J., Mazo, A., Nascimento, J., \& García-Rubio, J. (2018). The Relative Age Effect in under-18 basketball: Effects on performance according to playing position. PloS One, 13(7), e0200408.

Krahenbühl, T, \& Leonardo, L. (2020). The relative age effect: coaches' choices as evidence of social influence on youth handball. Journal of Physical Education and Sport, 20(5), Art 337, 2460-2467. DOI:10.7752/jpes.2020.05337. 
STUDIA SPORTIVA 2021/2

Loffing, F., Schorer, J., \& Cobley, S.P. (2010). Relative Age Effects are a developmental problem in tennis: But not necessarily when you're left-handed! High Ability Studies, 21(1), 19-25.

Malina, R. (1994). Physical growth and biological maturation of young athletes. Exercise and Sport Science Reviews, 22, 280-284.

Moreira, J., Lopes, M., Faria, L., \& Albuquerque, M. (2017). Relative Age Effect and Constituent Year Effect: An analysis of the international tennis federation ranking. Journal of Physical Education, 28(1), e2814. doi:10.4025/jphyseduc.v28i1.2814.

Musch, J., \& Grondin, S. (2001). c. Developmental Review, 21(2), 147-167.

Myburgh, G. K., Cumming, S. P., Coelho e Silva, M. J., Cooke, K., \& Malina, R. M. (2016). Growth and maturity status of elite British junior tennis players. Journal of Sports Sciences, 34(20), 1957-1964.

Nykodým, J., Bozděch, M., Agricola A., \& Zháněl, J. (2020). The Relative Age Effect at the Ice Hockey World Championships (IHWC) in the years 2015-2017. Journal of Human Kinetics, 74(4), 150-159. DOI: 10.2478/hukin-2020-0044.

O'Donoghue P. G. (2009a). Season-of-birth effects on elite junior tennis players' world rankings. In A. Lees, D. Cabello, \& G. Torres (eds). Science and Racket Sports IV, 275-281. London: Routledge.

O'Donoghue, P. (2009b). Relative age in elite tennis. Studies in Physical Culture and Tourism, 16(4), 379-388.

O'Donoghue, P. (2014). Relative age effect on elite tennis strategy for players born before and after 1st January 1985. International Journal of Performance Analysis in Sport, 14(2), 453-462.

Pacharoni, R., Aoki, M. S., Costa, E. C., Moreira, A., \& Massa, M. (2014). Efeito da idade relativa no Tênis. Revista Brasileira de Ciência e Movimento, 22(3): 111-117.

Parma, J. O., \& Penna, E. M. (2018). The relative age effect on Brazilian elite volleyball. Journal of Physical Education, 29, e2942.

Pintner, R., \& Forlano, G. (1934). The birth month of eminent men. Journal of Applied Psychology, 18(2), 178-188. https:// doi.org/10.1037/h0069821.

Ribeiro Júnior, E. J. F., Keller, B., Pereira, J. L., Coelho, R. W., Villas Boas, M. S., \& Grunevald, E. (2013). O fenômeno da idade relativa em atletas de tênis infantojuvenil e profissional: nível de associação com o ranking da federação sul-americana e mundial. Revista da Educação Física, 24(3), 371-379.

Romann, M., Rössler, R., Javet, M., \& Faude, O. (2018). Relative age effects in Swiss talent development - a nationwide analysis of all sports. Journal of Sports Sciences, 36(17), 2025-2031.

Rubia A.d.I., Bjørndal, C.T., Sanchez-Molina, J., Yague, J.M., Calvo, J.L., \& Maroto-Izquierdo, S. (2020). The relationship between the relative age effect and performance among athletes in World Handball Championships. PLoS ONE, 15(3), e0230133. https://doi.org/10.1371/journal.pone.0230133.

Savassifigueiredo, L., Ribeiro, L.C., Pereira Fialho, J.V.A.P, Da Silva, D.G., Gantois, P., Costa, G.C.T, \& Fonseca, F.S. (2020). Relative Age Effects and team performance among elite beach handballathletes. Journal of Physical Education and Sport, 20(6), Art 454, 3354-3360.

Söğüt, M., Luz, L. G. O., Kaya, Ö. B., Altunsoy, K., Dogan, A. A., Kirazci, S., Clemente, F. M., Nikolaidis, P. T., Rosemann, T., \& Knechtle, B. (2019). Age- and Maturity-Related Variations in Morphology, Body Composition, and Motor Fitness among Young Female Tennis Players. International Journal of Environmental Research and Public Health, 16, 2412. doi:10.3390/ ijerph16132412.

Sullivan, G. M., \& Feinn, R. (2012). Using effect size-or why the P value is not enough. Journal of Graduate Medical Education, 4(3), 279-282.

Thompson, A. H., Barnsley, R. H., \& Stebelsky, G. (1991). "Born to Play Ball”The Relative Age Effect and Major League Baseball. Sociology of Sport Journal, 8(2), 146-151.

Ulbricht, A., Fernandez-Fernandez, J., Mendez-Villanueva, A., \& Ferrauti, A. (2015). The Relative Age Effect and Physical Fitness Characteristics in German Male Tennis Players. Journal of Sports Science \& Medicine, 14(3), 634-642.

Vincent, J., \& Glamser, F. D. (2006). Gender differences in the relative age effect among US Olympic development program youth soccer players. Journal of Sports Sciences, 24, 405-413.

Contact: Roman Koloničný, E-mail: roma.kolo@icloud.com, Address: Dřevčice 147, 250 01, CZ 